tropyl alcohol, which is present in the solution and is brought by diffusion to the surface of the mercury electrode.

The reduction proceeds by a one-electron step to a radical, with subsequent formation of ditropyl, as in the reduction by zinc ${ }^{2}$. The formation of the dimer was proved ${ }^{3}$ by the shift of the half-wave potential with increasing tropylium bromide concentration. The half-wave potential at $p H$ lower than $\mathbf{4 \cdot 6}$ is independent on the $p \mathrm{H}$; at higher $p \mathrm{H}$ it shifts to more negative values according to the equation $E_{1 / 2}=-0.25-0.040 p \mathrm{H}$ (standard calomel electrode). The slope of the curves is 0.040 . All the phenomena observed are consistent with the mechanism indicated in Fig. 1.

Neither the character of the dissociation curves nor the $p K^{\prime}$ values are affected by the buffer components, by the pyridinium ions or by the ionic strength. Using the equation derived. by Kouteck $\dot{y}^{4}$ and the value $p K=4 \cdot 6$, determined by titration, the rate constant for the formation of tropylium ion was calculated as $k=2 \times$ $10^{8} 1$. mole $^{-1}$ sec. $^{-1}$.

At concentrations of the tropylium ion higher than about $0.001 M$, three types of adsorption processes were observed. Using the value for the lowest adsorption wave, the surface-area $(S)$, covered by one reduced seven-membered ring at the surface of the mercury drop, was calculated by Brdička's equation $^{5}$ as $29 \mathrm{~A} .^{2}$. Using covalent radii and bond distances $^{6}, S$ was calculated as $22 \mathrm{~A} .^{2}$. Adsorption processes were studied using $i-t$ curves, $\vec{v}-t$ curves, single sweep polarography, oscillographic polarography, etc. Detailed results will be published elsewhere.

We are indebted to Mr. C. R. Ganellin (Queen Mary College, University of London) for the sample of tropylium bromide.

Polarographic Institute,

Czechoslovak Academy of Science, Prague.

\section{P. ZUMAN}

J. Chonkowski

Department of Inorganic Chemistry, University of Warsaw.

\section{H. PotěšILOVA}

F. S̆ANTAVÝ

Department of Chemistry,

School of Medical Sciences,

Palackýs University,

Olomouc, Czechoslovakia. Sept. 10.

2 Volpin, M. E., Zdanov, S. I., and Kursanor, D. X., Doklady Akad. I Nauk S.S.S.R., 112, 264 (1957)

2 Doering, W. E. von, and Knox, L. H., J. Amer. Chem. Soc., 79, 352 (1957).

3 Hanus, V., Chem. Zvesti, 8, 702 (1954).

'[Koutecky, J., Chem. listy, 47, 323 (1953); Collect. Czechoslov. Chem. Commun., 18, 597 (1953).

${ }_{3}^{3}$ Brdicka, R., Collect. Czechoslov. Chem. Commun., 12, 522 (1947).

"Pauling, L., "The Nature of the"chemical Bond" (Cornell University Press, 19̈48).

\section{Origin of Time-dependent Organization in a Micelle Series}

THE question of physical equilibrium in homo. geneous solution may be stated as follows : At what stage of molecular complexity can a solute exist in non-equilibrium for times which are very long in relation to the scale of molecular processes? The complex linear micelles formed by the interaction of naphthol and a quaternary soap are able to exist ${ }^{1}$ and. contrary to expectation ${ }^{2}$, the simple micelles formed by the same soap alone ${ }^{8}$. The purpose of this communication is to show at what point in a homologous series such persistent non-equilibrium arises.

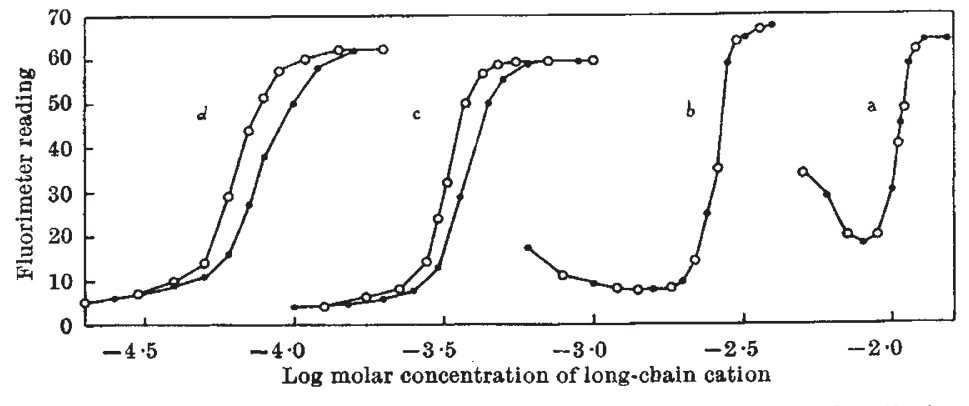

rescent dye in discriminating between different states of a cationic in $0.24 \mathrm{~m} M$ sulphate; $c$, C16 in $0.05 \mathrm{mM}$ sulphate and salt added to diluted soap
The compounds chosen were the $\mathrm{C12}, 14,16$ and 18 paraffin-chain trimethyl ammonium bromides, in aqueous solution around the critical micelle concentration, with a low concentration of sodium sulphate to develop the non-commutative property. This meant that the chemical potential could depend on the order in which the components were added (from relatively strong stock solution) as well as on the final composition. Sulphate was used rather than halide to minimize supersaturation ${ }^{4}$. Non-equilibrium was detected by fluorescence quenching, using dichlorofluorescein as the marker. The method depends on the sensitiveness of the dye/micelle adsorption complex to chemical potential; full details are being submitted elsewhere together with a theory based on accepted principles.

In numerous experiments at $25^{\circ} \mathrm{C}$. it was found that solutions of the $\mathrm{C} 12$ and $\mathrm{C} 14$ soaps were always completely defined by their composition, so that all the experimental points fell on a single curve (Fig. 1). This was not true for the others ; the curve split into two parts, the upper part referring to solutions in which sulphate had been added first, and the lower to those in which soap had been added first, as predicted by theory. The possibility of superimposable organization in homogeneous solution seems, therefore, to arise at a very early stage in molecular complexity, in micelles of a paraffin-chain salt with 16 or possibly 15 carbon atoms. Because of water-structure effects with quaternary compounds $\mathbf{s}^{4,5}$, not apparent with anionic ones, the critical chain-length is probably a little greater for the latter.

T. NASH

Central Public Health Laboratory, Colindale Avenue, London, N.W.9. Aug. 29.

1 Nash, T., Nature, 180, 188 (1957).

Hartley, G. S., Quart. Rev. Chem. Soc., 2, 152 (1948).

sash, T., J. App. Chem., 8, 440 (1958).

- Nash, T., Chem. and Indust., 590 (1958)

- Frank, H. S., and Wen-Yang ,Wen, Disc. Farad. Soc., 24, 133 (1957). 